\title{
From low to high latitudes: changes in fatty acid desaturation in mammalian fat tissue suggest a thermoregulatory role
}

\author{
Alicia I. Guerrero ${ }^{1,2^{*}}$ (D) and Tracey L. Rogers ${ }^{1}$
}

\begin{abstract}
Background: Most fatty acids (FAs) making up the adipose tissue in mammals have a dietary origin and suffer little modification when they are stored. However, we propose that some of those FAs, specifically those that can be synthesised or modified by mammals, are also being influenced by thermal forces and used as part of the mechanism to regulate core body temperature. As FA desaturation increases, adipose tissues can reach colder temperatures without solidifying. The ability to cool the superficial fat tissues helps create a thermal gradient, which contributes to body heat loss reduction. Therefore, it is expected that animals exposed to colder environments will possess adipose tissues with higher proportions of desaturated FAs. Here, through a model selection approach that accounts for phylogeny, we investigate how the variation in FA desaturation in 54 mammalian species relates to the thermal proxies: latitude, physical environment (terrestrial, semi-aquatic and fully-aquatic) and hair density.

Results: The interaction between the environment (terrestrial, semi- or fully-aquatic) and the latitude in which the animals lived explained best the variation of FA desaturation in mammals. Aquatic mammals had higher FA desaturation compared to terrestrial mammals. Semi-aquatic mammals had significantly higher levels of desaturated FAs when living in higher latitudes whereas terrestrial and fully-aquatic mammals did not. To account for dietary influence, a double bond index was calculated including all FAs, and revealed no correlation with latitude in any of the groups.

Conclusions: We propose that FA modification is an important component of the thermoregulatory strategy, particularly in semi-aquatic mammals. Potentially this is because, like terrestrial mammals, they experience the greatest air temperature variations across latitudes, but they lack a thick fur coat and rely primarily on their blubber. Unlike fully-aquatic mammals, extremely thick blubber is not ideal for semi-aquatic mammals, as this is detrimental to their manoeuvrability on land. Therefore, the adipose tissue in semi-aquatic mammals plays a more important role in keeping warm, and the modification of FAs becomes crucial to withstand cold temperatures and maintain a pliable blubber.
\end{abstract}

Keywords: Adipose tissue, Blubber, Environment, Fur, Insulation, Latitude, Acclimatization, Macroecology

\section{Background}

In spite of the thermal challenges of the aquatic medium, mammals have colonised this environment on seven separate occasions and have sucessfully adapted [1]. Mammals exploit a wide range of thermal habitats, from the tropics to the poles, and from high altitudes to deep oceans; thus, they

\footnotetext{
* Correspondence: aliciagv@live.cl

${ }^{1}$ Evolution and Ecology Research Centre, School of Biological, Earth and Environmental Sciences, University of New South Wales, Sydney 2052, Australia

${ }^{2}$ Centro de Investigación y Gestión de Recursos Naturales (CIGREN), Instituto de Biología, Facultad de Ciencias, Universidad de Valparaiso, Gran Bretaña, 1111, Valparaiso, Chile
}

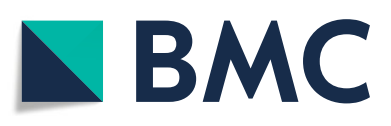

(c) The Author(s). 2019 Open Access This article is distributed under the terms of the Creative Commons Attribution 4.0 International License (http://creativecommons.org/licenses/by/4.0/), which permits unrestricted use, distribution, and reproduction in any medium, provided you give appropriate credit to the original author(s) and the source, provide a link to the Creative Commons license, and indicate if changes were made. The Creative Commons Public Domain Dedication waiver (http://creativecommons.org/publicdomain/zero/1.0/) applies to the data made available in this article, unless otherwise stated.

possess varied mechanisms to regulate their core body temperature. Changes in body size [2], hair density [3], metabolic rate [4], blubber thickness [5, 6], and blubber thermal conductivity [7] are some of these mechanisms, which have been well studied. However, the importance of the biochemical composition of the adipose tissue to mammalian thermoregulatory strategy has received less attention and yet is likely to be important, particularly where mammals use blubber as a thermal barrier.

Unlike other tetrapods, mammals have different insulation strategies, from fully furred through to totally naked forms, each with different thermal benefits and constraints. We propose that where mammals do not use fur, the adipose 
tissue is expected to play a more important role in keeping warm. In bare-skinned mammals, the cooling of the body surface in contact with air or water is of critical importance in order to reduce the heat lost to the environment. In cold superficial tissues occurs peripheral vasoconstriction, where the flow of warm blood is reduced [8], thus reducing body heat loss and creating a thermal gradient through the adipose tissue.

But cooling the body surface to temperatures similar to those of the ambient could create a potential problem. In extremely cold environments, low temperatures could cause rigidity and solidification of superficial tissues; potentially it is here when the biochemical structure of fats becomes more important.

Adipose tissues contain fat stored mostly in the form of triacylglicerol, which contains three molecules of fatty acids (FAs) [9]. The degree of desaturation of a FA is given by its number of double bonds within the chain [10]. As the degree of desaturation increases the tissues become more fluid and can reach colder temperatures for longer periods without solidifying [11]. An adipose tissue layer with higher degree of FA desaturation (FAs containing double bonds) is, therefore, better suited for lower temperatures as it is more effective for the maintenance of a thermal gradient.

The greatest contributor to adipose tissue FA composition is direct deposition of FAs from diet [9]. However, the FA composition of consumers rarely matches exactly that of their diet [12]; which suggests that there are other factors influencing FA metabolism. Since mammals have the ability to synthesize some of their FAs de novo or modify them [10], they do not necessarily have a direct dietary origin. Thus, it is possible to distinguish between dietary and endogenous FAs [13]. Dietary FAs are those that could only be derived from the diet as animals are unable to synthesize them, such as most polyunsaturated FAs (PUFAs) [14, 15]. Endogenous FAs are those that can be readily synthesized by the animal; most of them are saturated (SFAs) and monounsaturated FAs (MUFAs), although some of them may be partially obtained from diet $[13,14]$.

Although the properties of the adipose tissue will largely depend on the type of diet consumed, there is some evidence that supports the idea of a thermal influence in the metabolism of FAs. For example, northern aquatic and terrestrial mammals have higher proportions of MUFAs in their cold extremities compared to the rest of the body [15], suggesting that FA desaturation takes place when tissues are maintained at low temperatures to avoid solidification. Similarly, thirteen-lined ground squirrels exhibit higher MUFA-to-SFA ratios in their adipose tissues in winter compared to summer [16]. This suggests that certain changes in the FAs making up the adipose tissue are not only driven by diet but also by thermal acclimatization [15, 17-19]. The aim of this study was to evaluate whether thermal forces can have an effect on endogenous FAs in mammals. We hypothesise that animals living in colder environments, or those animals not relying on a fur coat, will have higher levels of FA desaturation in their adipose tissues.

To assess the hypothesis of thermal influence in FAs, we investigated the differences in degree of FA desaturation across a total of 54 mammalian species from terrestrial, semi-aquatic and fully-aquatic environments. We also investigated the patterns of FA desaturation across mammals inhabiting different latitudinal regions. The direct effect of ambient temperature is difficult to assess, since there is variation with season, water depth, and additionally, semi-aquatic mammals use two environments where depending on their lifestyle they can spend substantially more time in one than another. Therefore, in this study latitude was used as a coarse proxy for ambient temperature.

Fur-covered animals have skin temperatures closer to their body core whereas hairless animals have skin temperatures closer to those of the surrounding environment [20]. As most semi-aquatic mammals rely on a combination of both fur and blubber [19]; we investigated whether their FA desaturation is related to hair density.

We report here the patterns of FA desaturation as a function of latitude, in mammals inhabiting different physical environments, and discuss the potential drivers.

\section{Methods \\ Fatty acid data}

In total, we included $n=54$ mammalian species in this analysis. A database of FA composition for mammalian species ( $n=49$ species) was collated from the literature, sourced from the online databases ScienceDirect and Google Scholar, using the search terms 'fatty acids', 'lipids', 'adipose tissue,' fat' and 'blubber'. Where available, only the FA values of the outer blubber layer were used, as FAs within this layer are less influenced by diet $[12,18,21]$. Where data was obtained from juveniles and adults, only adults data was used. When FA values of females and males were reported separately, only values from males were used, as females may experience changes in FAs associated with pregnancy and lactation (Additional file 1: Table S1.). For terrestrial mammals, only white adipose tissue data were used.

The FA composition from other 5 species (3 otariids: subantarctic fur seal, Arctocephalus tropicalis; New Zealand fur seal, Arctocephalus forsteri; and Australian sea lion, Neophoca cinerea; and 2 cetaceans: pygmy right whale, Caperea marginata; and Risso's dolphin, Grampus griseus) was analysed from $0.3 \mathrm{~g}$ samples of outer blubber, using the SM Budge, SJ Iverson and HN Koopman [9] method to extract total lipids and prepare FA methyl esters. Gas chromatography analysis was 
performed as described in AI Guerrero and TL Rogers [22]. Blubber samples were sourced from animals stranded along the coast of Sydney, Australia. The FA composition of these species is available in Additional file 2: Table S2.

\section{Fatty acid desaturation}

To determine the degree of desaturation of endogenous FAs we calculated a desaturation index ( $\Delta 9$-DI). This indicates to what extent potentially endogenous MUFAs could have been synthesized by modification of their corresponding SFAs [19]. PUFAs were not included in this analysis, as most have a dietary origin [15]; therefore differences in proportions of PUFAs are likely to be a result of differences in diet. Using the percentage by weight per FA, a $\Delta 9$-DI was calculated according to the formula of A Käkëla and H Hyvärinen [15]:

$\Delta 9-D I=\frac{(w t \% 14: 1 \omega 5+w t \% 16: 1 \omega 7+w t \% 16: 1 \omega 9+w t \% 18: 1 \omega 9+w t \% 18: 1 \omega 7)}{(w t \% 14: 0+w t \% 16: 0+w t \% 18: 0)}$

where $\mathrm{wt} \%$, is the percentage by weight of the respective FA.

To account for the effect of dietary FAs on the desaturation of fat tissues, we calculated a double bond index (DBI), which includes all MUFAs and PUFAs, using the following formula [23, 24]:

$$
D B I=\frac{\sum x(w t \%)}{100}
$$

where $w t \%$, is the percentage by weight of each FA and $x$ is its number of double bonds.

\section{Explanatory variables}

The traits environment and latitude were collected for all 54 species in the database. Environment was categorised as terrestrial, semi-aquatic or fully-aquatic; where terrestrial mammals $(n=15)$ are those whose complete life cycle takes place on land only; semi-aquatic species $(n=25)$ are those who rely on both land (or ice) and water for breeding and feeding; and fully-aquatic species $(n=14)$ are those who spend their entire lives in water. Latitude corresponds to the location where the blubber samples were collected.

Hair density values, number of hairs per area $\left(\mathrm{mm}^{2}\right)$, were obtained from the literature for most semi-aquatic mammals $(n=22)$, using the search terms 'fur density' and 'hair density' plus the species name, on ScienceDirect and Google Scholar. When primary and secondary hair densities were calculated separately, we added them up and used total hair density. Values were logtransformed for analysis.

\section{Data analysis}

We used a model selection approach to test whether factors could explain the variation of $\Delta 9$-DIs (potentially endogenous FAs) or DBI (total FAs) in mammals. Initially, with the entire dataset ( $n=54$ species), we included the factors environment, latitude, or a combination of these variables, and then, with a smaller dataset of 22 semiaquatic mammals we included the factors latitude, fur density, or a combination of these variables.

In detail, for the entire mammalian FA desaturation dataset $(\Delta 9$-DI or DBI) we tested the following models: (a) an additive model containing the two variables $\left(\beta_{0}+\right.$ $\beta_{\text {environment }}+\beta_{\text {latitude }}$ ); (b) an environment and latitude interaction model $\left(\beta_{0}+\beta_{\text {environment }}{ }^{*} \beta_{\text {latitude }}\right) ;$ models where each variable would be the sole predictor for the desaturation of FAs: (c) a latitude model $\left(\beta_{0}+\beta_{\text {latitude }}\right)$ or (d) environment model $\left(\beta_{0}+\beta_{\text {environment }}\right)$; and (e) a Null model $\left(\beta_{0}\right)$.

Another series of models tested the relationship between hair density, latitude and $\Delta 9$-DI in semi-aquatic mammals. For this data subset, we tested: (a) an additive model containing two variables $\left(\beta_{0}+\beta_{\text {latitude }}+\beta_{\text {hair_den- }}\right.$ sity); (b) models to test for different slopes of hair density with latitude $\left(\beta_{0}+\beta_{\text {latitude }} \beta_{\text {hair_density }}\right)$; and (c) a hair density model $\left(\beta_{0}+\beta_{\text {hair_density }}\right)$, (d) a latitude model $\left(\beta_{0}+\beta_{\text {latitude }}\right)$ and (e) a Null model $\left(\beta_{0}\right)$.

To identify the model(s) with best support, we calculated the Akaike's information criterion (with a correction for sample size; $A I C c$ ) and the Akaike weight [25-27] for each model.

To account for the potential that phylogenetic relatedness confounds the variation in mammalian $\Delta 9$-DIs or DBI, we used phylogenetic generalised least squares (PGLS) analysis [28]. PGLS uses a lambda $(\lambda)$ value, an estimate of phylogenetic correlation, that varies between 0 (indicating phylogenetic independence) and 1 (indicating that variation of traits between species covary proportionally with their phylogenetic relatedness) $[29,30]$. We used the S Faurby and J-C Svenning [31] mammalian supertree and included 1000 random iterations to resolve possible polytomies. Two trees were pruned to include only the species present in our dataset, the first including all mammals for which we had data $(n=54)$, the second tree including only the semi-aquatic mammals for which hair density data was available $(n=22)$. The $\mathrm{R}$ (version 3.0.1) [32] packages, 'phytools' [33] and 'caper' [34] were used for tree manipulation and PGLS analyses, respectively. For models with the highest support, we extracted the $95 \%$ confidence intervals (CIs) and significance was deemed when the CIs did not overlap 0.

In order to identify which individual FAs drive changes in desaturation, when $\Delta 9$-DI was found to be significantly correlated with latitude, we applied linear regression analyses to those individual SFAs and MUFAs used to calculate the $\Delta 9$-DI.

Stratification of blubber FAs has been reported for most marine mammals [22] where the outer layer usually has greater proportions of MUFAs and smaller 
amounts of SFAs compared to the inner layer. Thus, to determine whether the use of different blubber sections (whole blubber core vs outer layer) would affect our analyses, we run an independent PGLS analysis for pinniped species for which either the outer layer $(n=14)$ or the whole blubber $(n=6)$ was used. We did not do the same for fully-aquatic mammals, as most FA values were obtained from the outer layer, with only two exceptions (Additional file 2: Table S2.).

Values are presented as mean \pm standard deviation (SD) unless otherwise noted.

\section{Results}

\section{Desaturation of endogenous fatty acids}

The desaturation of endogenous FAs, $\Delta 9$-DI, was best explained by the interactive model (Table 1 ) including environment and latitude $\left(\beta_{0}+\beta_{\text {environment }}\right.$ " $\left.\beta_{\text {latitude }}\right)$. This model received the most support and accounted for $33 \%$ of the variance $(r=0.57)$, although the additive model including environment and latitude $\left(\beta_{0}+\beta_{\text {environment }}+\beta_{\text {latitude }}\right)$ had $\triangle$ AICc values within 2 units, which suggests that this model was equally supported. The Akaike weights showed that the interactive model was 2.7 times more likely to be the driver of mammalian $\Delta 9$-DI than the additive model. The PGLS $\lambda$ value was 0.47 ; suggesting that the variation of $\Delta 9$-DI is not entirely dependent of phylogeny.

Fully-aquatic mammals have a mean $\Delta 9$-DI of $3.08 \pm 1.07$, whereas semi-aquatic mammals have a $\Delta 9$-DI of $3.09 \pm 1.75$, and terrestrial mammals have a lower $\Delta 9$-DI of $1.37 \pm 0.70$. Among the three environments, only the $\Delta 9$-DI of semi-aquatic species had a significant positive correlation (CIs do not overlap 0 ) with latitude (slope $=0.06$, CIs $=0.02,0.11$ ), such that semi-aquatic mammals at higher latitudes have significantly greater $\Delta 9$-DI values than species at lower latitudes (Fig. 1b). In comparison, the $\Delta 9$-DI values of fully-aquatic (slope $=0.02$, CIs $=-0.02,0.05$ ) and terrestrial (slope $=-0.01$, CIs $=-0.08,0.05$ ) mammals do not show a relationship with latitude (Fig. 1a and c).

Pinnipeds for which only the outer layer was used, still displayed a significant correlation between $\Delta 9$-DI values and latitude (slope $=0.07, \mathrm{CIs}=0.04,0.11$; Fig. 2); however, those pinniped species for which the whole blubber core was used, displayed a non-significant but positive correlation between $\Delta 9$-DI and latitude (slope $=0.03, \mathrm{CIs}=-0.03,0.09$ ).

\section{Desaturation of total fatty acids}

The DBI including all dietary and endogenous desaturated FAs was best explained by the environment model $\left(\beta_{0}+\right.$ $\beta_{\text {environment }}$ ), which received the most support, explaining $50 \%$ of the variance $(r=0.70)$. The other model with $\triangle \mathrm{AICc}$ value within 2 units was the additive model $\left(\beta_{0}+\beta_{\text {environ- }}\right.$ ment $\left.+\beta_{\text {latitude }}\right)$, which suggests that this model is equally supported; however, the addition of latitude only explains an additional variance of $0.1 \%$. In addition, environment model was 1.8 times more likely to be the driver of DBI in mammals than the additive model (Table 1). The PGLS $\lambda$ value was closer to $1(0.70)$, suggesting that DBI covaries in proportion to the degree of shared evolutionary history.

Fully-aquatic mammals have a mean DBI of $1.25 \pm 0.36$, whereas semi-aquatic mammals have a DBI of $1.61 \pm 0.36$ and terrestrial mammals a lower value of $0.85 \pm 0.18$ (Fig. 3). Intercept values were significantly different between fullyaquatic and terrestrial mammals (CIs $=-0.67,-0.18)$, and between fully-aquatic and semi-aquatic mammals $(\mathrm{CIs}=$ $0.11,0.55)$.

\section{Effect of hair density and latitude on fatty acids of semi- aquatic mammals}

When we included hair density as a variable for the $\Delta 9$ DI of semi-aquatic mammals, we found that the model

Table 1 A comparison of the level of support for possible explanatory models that describe the variation in desaturation of endogenous (Desaturation index: $\triangle 9$-DI) and total fatty acids (Double bond index: DBI) in mammals $(n=54)$

\begin{tabular}{|c|c|c|c|c|}
\hline Model & $\triangle \mathrm{AlCC}$ & PGLS $\lambda$ & Effect size $(r)$ & Weighted AICc \\
\hline \multicolumn{5}{|l|}{ Desaturation index $(\Delta 9-\mathrm{DI})$} \\
\hline$\beta_{0}+\beta_{\text {latitude }} * \beta_{\text {environment }}$ & 0.0 & 0.47 & 0.57 & 0.65 \\
\hline$\beta_{0}+\beta_{\text {latitude }}+\beta_{\text {environment }}$ & 2.0 & 0.44 & 0.50 & 0.24 \\
\hline$\beta_{0}+\beta_{\text {latitude }}$ & 4.2 & 0.61 & 0.36 & 0.09 \\
\hline$\beta_{0}+\beta_{\text {environment }}$ & 7.0 & 0.37 & 0.38 & 0.02 \\
\hline$\beta_{0}$ & 9.1 & 0.56 & - & 0.01 \\
\hline \multicolumn{5}{|l|}{ Double bond index (DBI) } \\
\hline$\beta_{0}+\beta_{\text {environment }}$ & 0.0 & 0.00 & 0.70 & 0.61 \\
\hline$\beta_{0}+\beta_{\text {latitude }}+\beta_{\text {environment }}$ & 1.2 & 0.00 & 0.69 & 0.33 \\
\hline$\beta_{0}+\beta_{\text {latitude }} * \beta_{\text {environment }}$ & 4.6 & 0.00 & 0.72 & 0.06 \\
\hline$\beta_{0}$ & 14.0 & 0.68 & - & 0.00 \\
\hline$\beta_{0}+\beta_{\text {latitude }}$ & 16.3 & 0.68 & 0.04 & 0.00 \\
\hline
\end{tabular}

The results are produced from phylogenetic generalised least squares (PGLS) analysis across 1000 alternate resolutions of mammalian phylogeny 

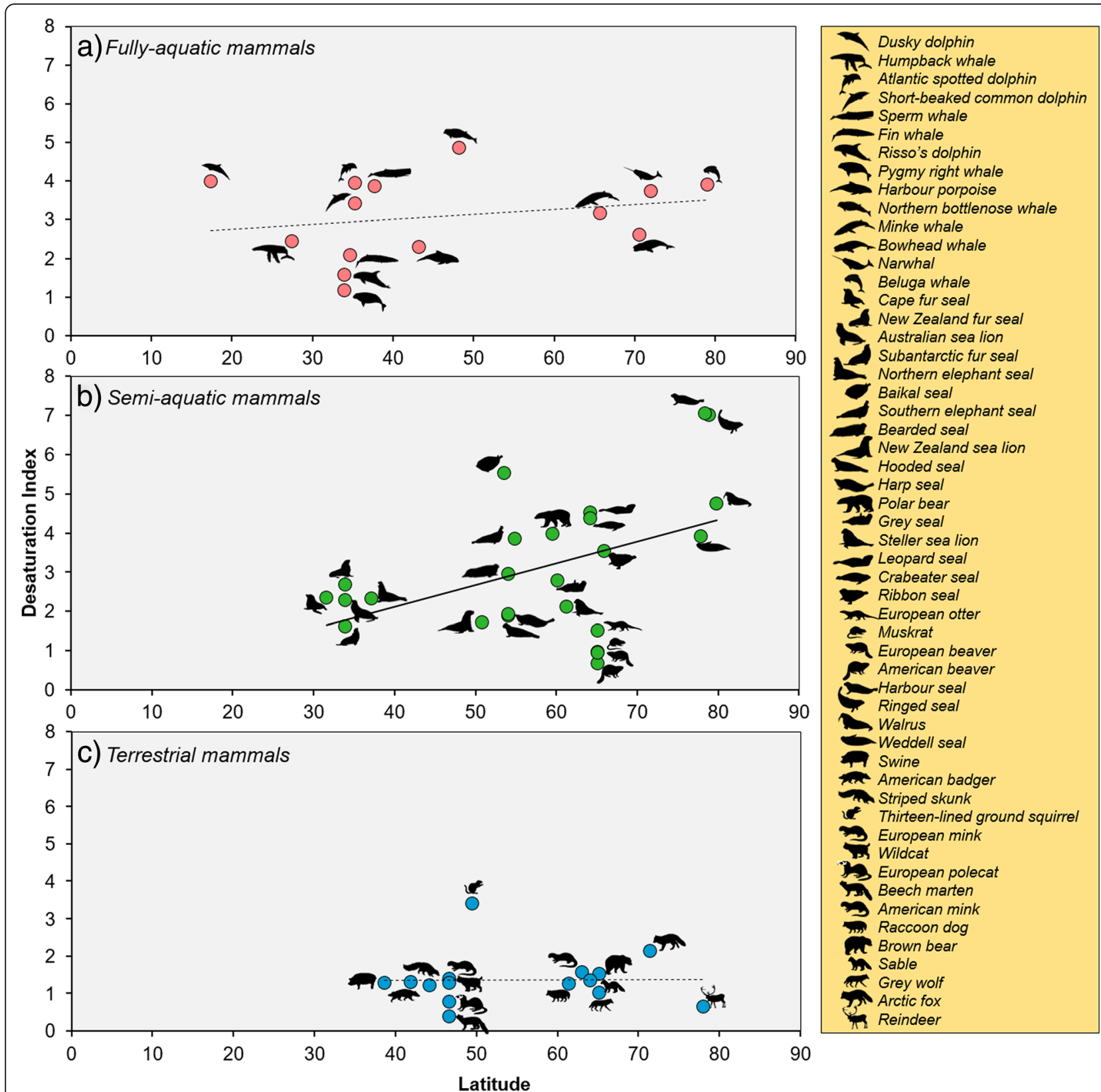

Latitude

Fig. 1 Desaturation index of fatty acids as a function of latitude for mammals inhabiting different environments. Dashed (non-significant correlation) and solid (significant correlation) lines indicate the phylogenetic generalised least squares (PGLS) regression lines for: a fully-aquatic $(y=0.02(x)+2.27 ; n=14)$; $\mathbf{b}$ semi-aquatic $(y=0.06(x)-1.34 ; n=25)$; and $\mathbf{c}$ terrestrial mammals $(y=-0.01(x)+1.62 ; n=15)$. Only the blubber of semi-aquatic mammals displayed significantly $(\mathrm{Cl} s=0.02,0.11)$ higher fatty acid desaturation when living in colder latitudes. Silhouettes are listed in the same order as they appear in each plot, from left to right and top to bottom. Scientific names can be found in Additional file 1: Table S1

with the best support was the latitude model $\left(\beta_{0}+\beta_{\text {latitude, }}\right.$ Table 2), which explains $35 \%$ of the variance $(r=0.60)$. The PGLS $\lambda$ was 0.45 ; and there were no other models within 2 $\triangle \mathrm{AICc}$ units. Including these 22 species, there was a positive significant correlation between latitude and $\Delta 9$-DI (slope $=0.08$, CIs $=0.03,0.12$ ). Hair density only explained an additional $2 \%$ of the variance in the second-best model $\left(\beta_{0}+\beta_{\text {hair_density }}+\beta_{\text {latitude }}\right)$, which had an $\Delta$ AICc of 2.5 .

\section{Variation of individual fatty acids with latitude}

Linear regression analysis was only applied to pinniped species, as the correlation between $\Delta 9$-DI and latitude seems to be a pinniped-only pattern. Most MUFAs increased significantly $(P<0.01)$ with latitude whereas most SFAs $(P<0.01)$ decreased significantly (Fig. 4).

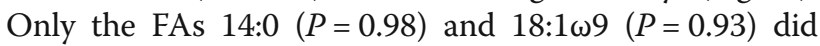
not show variation with latitude. 


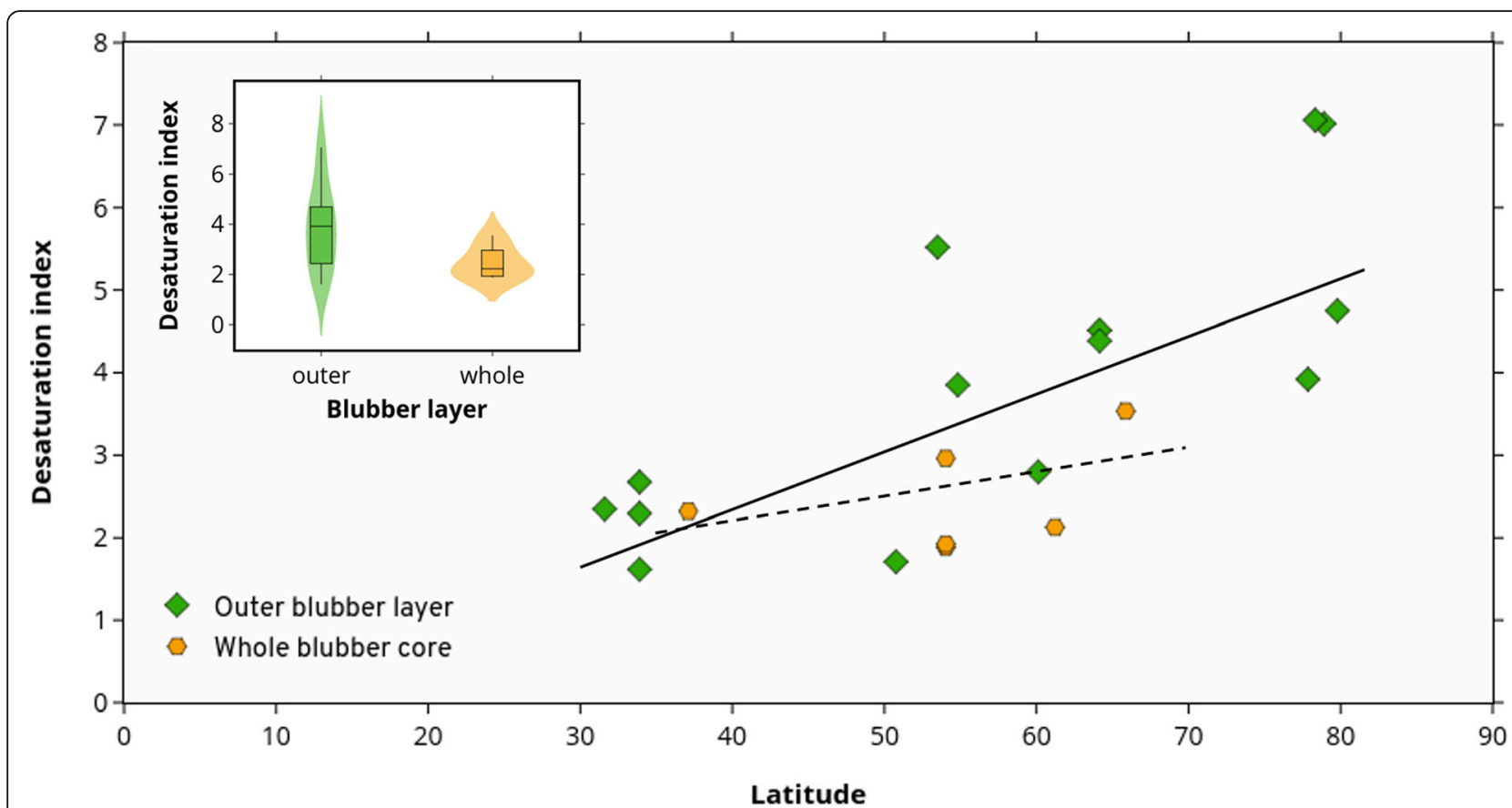

Fig. 2 Desaturation index of blubber fatty acids as a function of latitude for pinnipeds, separated by blubber section used for analyses: whole blubber core (from skin to muscle; $n=6$ ) or only the outer layer (section just beneath the skin; $n=14$ ). Based on phylogenetic generalised least squares (PGLS), the dashed regression line indicates a non-significant correlation for whole blubber fatty acids $(y=0.03(x)+1.01)$ whereas the solid line indicates significant correlation for outer blubber fatty acids $(y=0.07(x)-0.41)$

\section{Discussion}

We show that the environment is potentially an important driver of FA desaturation in mammals. The variable environment was consistently important whether dietary FAs were considered (DBI), or not $(\Delta 9-\mathrm{DI})$. Conversely, latitude was an important driver only for $\Delta 9$-DI. The latitude in which the mammal lived was important for semi-aquatic mammals but it was not for terrestrial and fully-aquatic mammals. This study provides insights to whether this is only because the environment offers different FAs through its food webs, or also due to the demands each environment imposes which leads to intrinsic modification of FAs.

\section{Effects of latitude and environment on fatty acids}

The best model of $\Delta 9$-DI included an interaction between environment and latitude. Aquatic mammals had higher degrees of desaturation than terrestrial mammals (Fig. 1), as expected. The aquatic medium has higher cooling potential than air [35], which suggests that the biochemical composition of adipose tissues plays a more important role in thermoregulation in aquatic mammals. Additionally, aquatic mammals use blubber as primary insulator whereas most terrestrial species use fur.

In fully-aquatic mammals, although there was a small positive correlation between $\Delta 9$-DI and latitude, this was not significant (Fig. 1a). Because fully-aquatic mammals rely solely on their blubber as a thermal insulator [19], this outcome was not expected. In bare-skinned animals, the skin and superficial tissues become very cold when they are exposed to low environmental temperatures [4]. In whales, for example, the skin temperature has been found to equal that of the water [20]. Therefore, the question is, why do fully-aquatic mammals not display greater degree of FA desaturation when they live in higher (colder) latitudes?

There are limitations to the study that could help us understand the absence of a pattern. Although the relationship between desaturation and latitude was positive, it was not significant, which can be due to the small sample size. In addition, we used whole blubber FAs for two of the species living in the highest latitudes: the narwhal, Monodon monoceros, and the beluga whale, Delphinapterus leucas (Fig. 1); whereas for all other fully-aquatic species we used the outer blubber layer. Since the blubber of marine mammals is stratified, where MUFAs are more abundant in the outer layer and SFAs in the inner layer [22], the use of whole blubber FAs should reduce the MUFA-to-SFA ratio leading to a decrease in $\Delta 9$-DI. If we had the data of the outer layer $\Delta 9$-DI instead, the values should be higher which could have led to a significant correlation. Unfortunately, it is difficult to measure the magnitude of the effect of the blubber section utilised, due to the small sample size.

Nevertheless, there is an aspect of FA composition not accounted for in this study. Certain families of cetaceans synthesise considerable levels of the endogenous 

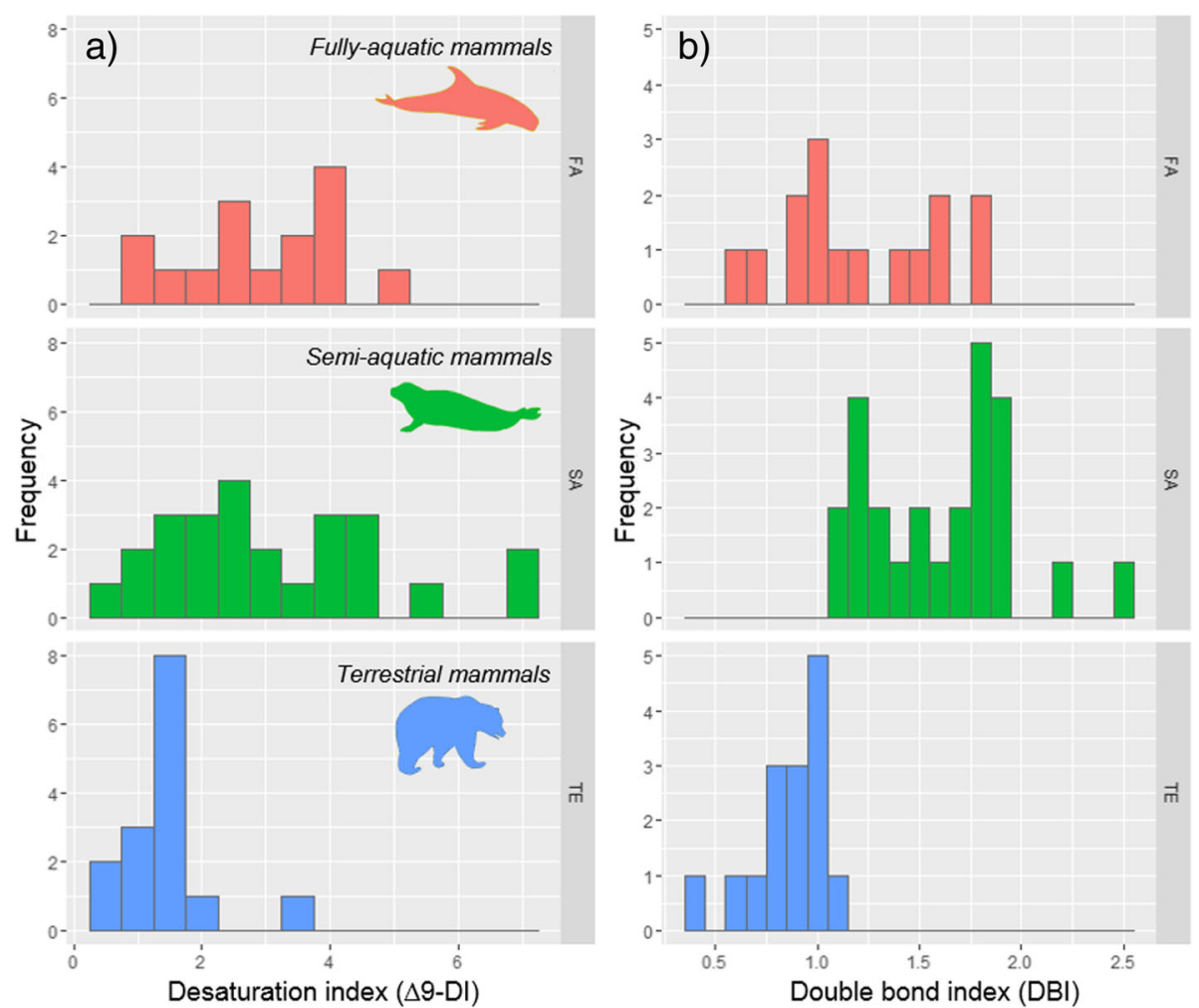

Fig. 3 Histogram of a desaturation ( $\triangle 9-D I$ ) and $\mathbf{b}$ double bond index (DBI) of terrestrial (TE), semi-aquatic (SA), and fully-aquatic (FA) mammals. DBI has been calculated using all monounsaturated and polyunsaturated fatty acids, whereas $\Delta 9$-DI was calculated using only endogenous fatty acids

isovaleric acid, a short branched-chain FA [36]. This FA has an extremely low melting point of $-37.6^{\circ} \mathrm{C}$ [37], and it has been found in great quantities (e.g.: 35\% in Hector's dolphin, Cephalorhynchus hectori) in the outer blubber layer of some odontocetes [36]. They are hypothesised to play a role in maintaining blubber pliability in cold environments as they have been found to be more abundant in species inhabiting colder waters $[9,36]$. Therefore, potentially some fully-aquatic mammals would rather synthesise this or other branched-chain FAs than increase their desaturation levels. Still, the synthesis of this FA is not ubiquitous among cetaceans; therefore, this does not completely explain the little variation of desaturation with latitude.

Table 2 A comparison of the level of support for possible explanatory models that describe the variation in desaturation of endogenous fatty acids (Desaturation index: $\Delta 9-\mathrm{DI}$ ) in semiaquatic mammals $(n=22)$

\begin{tabular}{lllll}
\hline Model & $\triangle$ AICC & PGLS $\lambda$ & Effect size $(r)$ & Weighted AICc \\
\hline$\beta_{0}+\beta_{\text {latitude }}$ & 0.0 & 0.45 & 0.60 & 0.67 \\
$\beta_{0}+\beta_{\text {latitude }}+\beta_{\text {hair_density }}$ & 2.5 & 0.53 & 0.61 & 0.19 \\
$\beta_{0}+\beta_{\text {latitude }} \beta_{\text {hair_density }}$ & 4.1 & 0.00 & 0.63 & 0.09 \\
$\beta_{\text {hair_density }}$ & 6.0 & 0.00 & 0.38 & 0.03 \\
$\beta_{0}$ & 6.5 & 0.22 & - & 0.03 \\
\hline
\end{tabular}

The results are produced from phylogenetic generalised least squares (PGLS) analysis across 1000 alternate resolutions of mammalian phylogeny
However; do fully-aquatic mammals need to maintain a pliable blubber in cold environments? The need for a pliable blubber might not be such for cetaceans. Some toothed whales (e.g. beaked and sperm whales) have FAs in the form of wax esters instead of triacylglycerols [38]; these wax esters have relatively high melting points [39], which makes them solid at most of the temperatures they find in the surrounding water. This implies that these species have rather rigid blubber layers, which does not seem to be an inconvenient for them.

Terrestrial mammals displayed low values of $\Delta 9$-DI and DBI, compared to the other groups (Fig. 3) and they did not exhibit a relationship between $\Delta 9$-DI and latitude (Fig. 1c). Although terrestrial mammals living in arctic climates encounter great diurnal and seasonal temperature variations [40], they seem to have little need for lowering the solidifying point of their adipose tissue. Our observations concur with those of PF Scholander, V Walters, R Hock and L Irving [41], who state that body fat does not seem to play any role in the insulation of terrestrial arctic mammals. In fact, fur has been found to be a more efficient insulator than adipose tissue [41], since it creates the same thermal gradient between body core and body surface, but across a much smaller thickness [19].

In the case of animals with poor insulating fur (thin, sparse fur or hairless), the thermal role of adipose tissues 


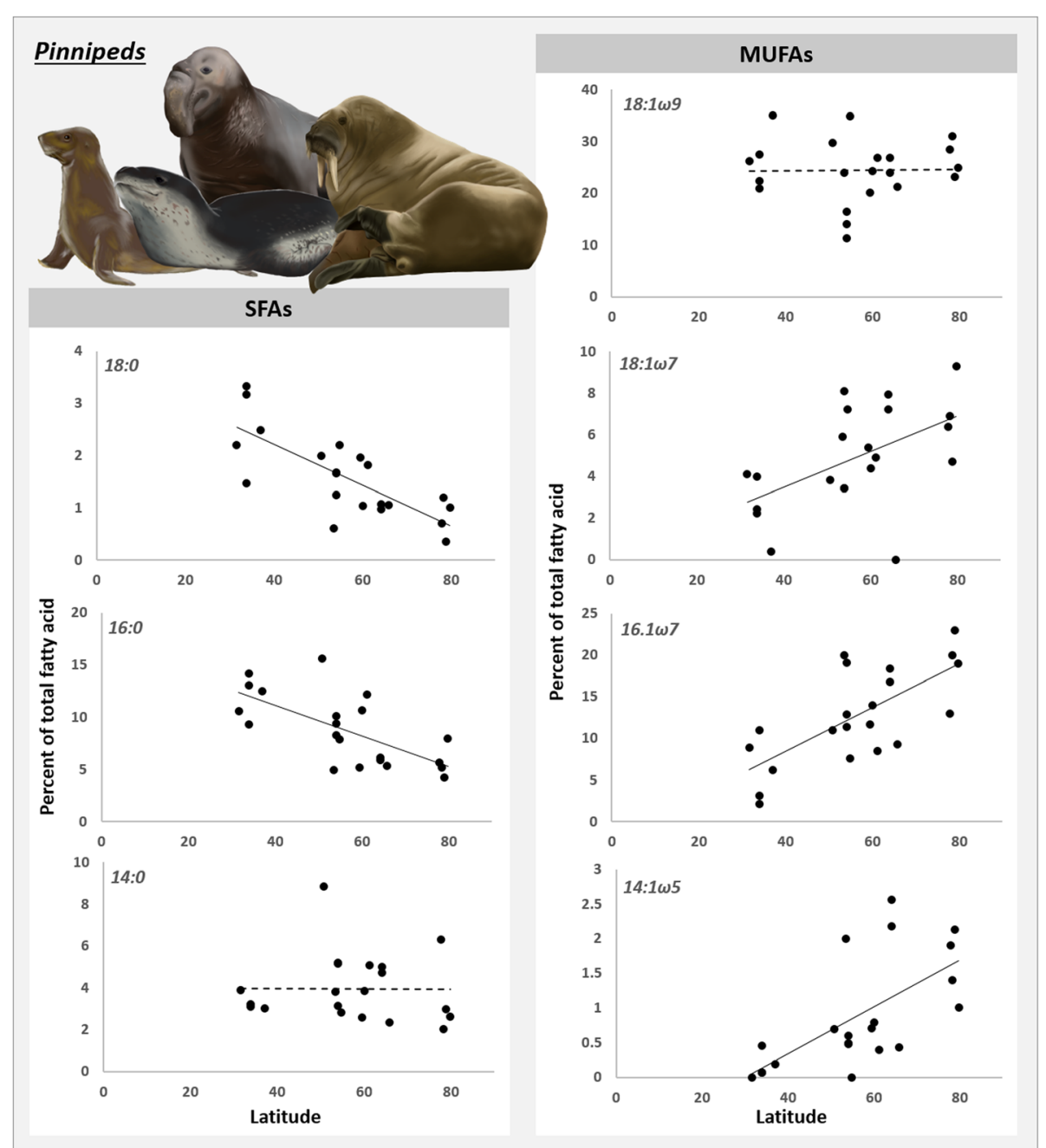

Fig. 4 Percentage of saturated (SFAs) and monounsaturated (MUFAs) fatty acids as a function of latitude, for pinniped species. Dashed trend lines indicate no significant correlation between latitude and percent of fatty acid, and solid lines indicate significant correlation. These fatty acids were used to calculate the desaturation index

is expected to gain importance. V Henriques and $\mathrm{C}$ Hansen [42] compared groups of pigs living at $0^{\circ} \mathrm{C}$ : one group with their skin directly exposed to the cold ambient air and the other where animals had a sheepskin garment. After 2 months, bare-skinned pigs had adipose tissues that solidified at a temperature $2.4^{\circ} \mathrm{C}$ lower than pigs protected by a coat. This suggests an increase in the degree of desaturation in the FAs of pigs whose skin was in direct contact with the cold environment. Both groups were fed the same food; therefore, this could be either a result of the modification of their FAs or the selective incorporation of certain FAs from the diet to fulfil their thermal needs. Low tissue temperatures, therefore, seem to affect the desaturation of FAs. Conversely, when the skin temperature is maintained close to the warm body temperature, as it is the case of garmentcovered pigs and fur-covered mammals, a modification of FAs may not be necessary.
Semi-aquatic mammals, unlike the other two groups, have higher $\Delta$ 9-DI as they inhabit higher latitudes (Fig. 1b). When hair density was included in the analysis, latitude was still a more important driver of $\Delta 9$-DI (Table 2). Conversely, DBI, which included dietary FAs, did not change with latitude, which suggests that this relationship between desaturation of FAs $(\Delta 9-\mathrm{DI})$ and latitude is not due to differences in diet.

The blubber section used for analysis seems to affect at some degree the $\Delta 9$-DI, as values of whole blubber cores where usually lower than those of outer layer, for animals living in similar latitudes. Thus, when only the outer layer was used, the correlation between $\Delta 9$-DI and latitude for pinnipeds is stronger, with a steeper slope (Fig. 2). However, since the number of data points obtained from whole blubber cores was relatively small ( $n=6$, versus $n=25$ for all semiaquatic species), this did 
not alter the correlation found between $\Delta 9$-DI and latitude in semiaquatic mammals.

Figure 4 allows us to infer some of the mechanisms behind the increased FA desaturation in colder regions.

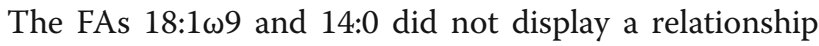
with latitude, suggesting that they do not have an important role in the increased FA desaturation of pinnipeds exposed to colder temperatures. The other FAs, however, behaved as expected; the SFAs 16:0 and 18:0 decreased with latitude whereas the MUFAs 14:1 $\omega 5,16$ : $1 \omega 7$ and $18: 1 \omega 7$ increased.

The effect of temperature on FAs has been well documented for organisms at lower trophic levels. The most commonly observed change in FAs following a temperature shift is an alteration in desaturation. In carp fish, for example, the expression of the enzyme that incorporates the first unsaturation bond into saturated FAs, $\Delta 9$-desaturase, is induced by cold temperature [43]. Similarly, an increase of FA desaturation when exposed to lower environmental temperatures has been reported for algae and copepods [44-46]. Since mammals exert sensitive control over their desaturases [47], coldinduced mechanisms could be regulating their increase of MUFAs and decrease of SFAs at higher latitudes. Although this broad analysis does not allow us to determine the biochemical paths behind these patterns; we expect that these findings encourage further investigation on the thermoregulatory mechanisms of blubber.

Therefore, why are semi-aquatic mammals the only group that modifies its FAs intrinsically as a response to ambient temperatures? Semi-aquatic mammals are the only ones that move between two environments. Switching from one environment to another implies that animals are exposed to contrasting temperatures and very different heat loss rates. Additionally, they possess both fur and blubber insulation, which is an interesting aspect of mammalian thermoregulation. The presence of dense, waterproof fur is a characteristic of recent entries to the aquatic environment, such as otters, beavers and other rodents $[19,48]$. In this study, muskrats, beavers and otters, although living in cold regions, were the species with the lowest degrees of desaturation (Fig. 1b) suggesting that this is a pinniped-only phenomenon. Interestingly, these recent entries to the aquatic medium have the highest hair densities (See Additional file 1: Table S1.). This supports the idea that these mammals rely on dense waterproof fur, rather than the adipose tissue, as an insulator [48]. The efficiency of this coat relies on the air trapped in its hairs [49], which forms a protective warm layer and keeps the skin relatively dry [50]. This thermal barrier, however, can be a disadvantage in swimming performance.

Earlier entries to the aquatic environment, such as pinnipeds, have become much better swimmers, and this has implied the reduction of drag through more streamlined bodies [51], reduction of fur density and thickness [52], and the transition to blubber as an insulator [19]. They possess a wettable fur that is not a good insulator in water, as the air layer trapped in the fur is released due to compression when diving [19]; thus, blubber becomes more important as a thermal barrier.

A thick blubber layer could ensure an effective insulation in water, which is the case of most fully-aquatic mammals, but for a semi-aquatic mammal an extremely thick blubber layer can be problematic. Most semi-aquatic mammals are relatively small compared to cetaceans, and an extremely large blubber layer would impede an agile terrestrial locomotion, especially for those animals living in rookeries with steep slopes, which is common amongst sea lions and fur seals. A trade-off, having a not too thick, but efficient thermal insulator is therefore imperative. A variation in FA composition can be an effective mechanism to maintain a good insulating layer without limiting the manoeuvrability of these animals. Higher FA desaturation in higher latitudes allows the blubber layer near the skin to lower its temperature and therefore reduce heat loss to the surrounding environment due to peripheral vasoconstriction. This feature can be more important in pinnipeds than in any of the other two groups, as they cannot afford a very thick pelage like terrestrial mammals, and neither can they develop extremely thick blubber as fully-aquatic mammals.

Additionally, air temperature variations could explain why semi-aquatic mammals are significantly influenced by latitude and fully-aquatic mammals are not. The water temperature may vary widely, from $30^{\circ} \mathrm{C}$ to about $-2{ }^{\circ} \mathrm{C}$, from the tropics to the poles, whereas air temperature in the poles can easily drop to about $-25^{\circ} \mathrm{C}$ in winter [53]. Therefore, semi-aquatic mammals are experiencing the most extreme temperature variations and, in absence of an insulating fur coat, the modification of FA desaturation in higher latitudes is a good solution to avoid tissue solidification.

Another interesting aspect of blubber is that it has been reported to display thermal behaviour consistent with phase change materials [54]; thus, using biochemical bonds to store and release heat when lipids melt or solidify at certain temperatures $[55,56]$. Many of the FAs found in the blubber are classified as phase change materials [57]; they have melting points between $29^{\circ}$ and $38^{\circ} \mathrm{C}$ [55] which are within mammalian body temperatures. This suggests that changes in desaturation of FAs might not only be related to pliability but also thermal storage; however, this needs further investigation.

\section{Dietary influence}

The influence of diet in the FA composition of mammals is undeniable, and this is why the use of FAs as trophic markers is gaining scientific attraction $[14,58]$. However, 
there are many factors that can affect the composition of FAs and we show here that the effect of thermal acclimatization is potentially one of them.

To calculate $\Delta 9$-DI, we used only those FAs that can be intrinsically synthesised; however, some FAs can be partially endogenous and partially dietary [14]. This is a limitation to this type of analysis. It can be argued that diet still has an influence in the desaturation of FAs. A recent study by SK Abbott, PL Else, TA Atkins and AJ Hulbert [59] shows that rats fed 12 diets showed changes in their MUFA content. In this study, when rats were fed fat that was high in MUFAs the adipose FA composition became increasingly higher in MUFAs, and vice versa. However, there are other examples where diet has had little influence on MUFAs and SFAs. For instance, in humans, PUFAs show a close relationship between dietary intake and adipose tissue whereas SFAs and MUFAs are less closely correlated [60]. Radiolabelling studies showed that grey seals transformed SFAs into MUFAs because the radio-labelled palmitic acid 16:0 they were fed was modified into 16:1 in their blubber [61]. Other authors agree that MUFAs and SFAs are not expected to reflect dietary intake [62]. In this study, there could still be a dietary influence in the FA desaturation of mammals, however this multi-species approach allows us to see that, when examined more broadly, there is an interesting influence of thermoregulation on FAs and that this is a fertile area to investigate further.

\section{Conclusions}

We show that the ability to modify FAs is an important part of mammalian thermal plasticity, especially for mammals living under adverse thermal conditions. We demonstrate that fully-aquatic mammals have increased FA desaturation in their blubber compared to terrestrial mammals, but they do not modify their FAs in different latitudes; they are potentially regulating other parameters of blubber instead. Terrestrial mammals rely mainly on fur as insulator; thus, their adipose tissues have low levels of FA desaturation which does not vary in colder latitudes. Semi-aquatic mammals increase their FA desaturation when living in colder regions, so that they can cool their superficial tissues near freezing temperatures without solidification. The ability to modify their FAs is imperative in semi-aquatic species, as they cannot afford to have extremely thick blubber layers as fully-aquatic mammals since this would compromise their ability to move on land. Additionally, they are exposed to the greatest temperature variations, just like terrestrial mammals, but they lack an insulating fur coat and, therefore, modify their blubber biochemical composition.

\section{Additional files}

Additional file 1: Table S1. Data collected across 54 mammalian species. Blubber section indicates whether samples analysed correspond to the whole core of blubber or just the section closer to the skin (outer layer). Data sources are indicated for fatty acid and hair density data. The desaturation index $(\triangle 9-\mathrm{DI})$ and Double bond index (DBI) calculated are also provided. (DOCX $87 \mathrm{~kb})$

Additional file 2: Table S2. Fatty acid composition of 5 mammal species. Samples of the outer blubber layer were collected from stranded animals along the coast of Sydney, Australia. (DOCX $23 \mathrm{~kb}$ )

\section{Abbreviations}

$\triangle 9$-DI: Desaturation index; AICc: Akaike information criterion (corrected for sample size); Cls: Confidence intervals; DBI: Double bond index; FA(s): Fatty $\operatorname{acid}(s) ;$ MUFA(s): Monounsaturated fatty acid(s); PUFA(s): Polyunsaturated fatty acid(s); SFA(s): Saturated fatty acid(s)

\section{Acknowledgements}

We would like to thank every member of the Mammal Lab at UNSW for their support and helpful feedback on our manuscript, and especially Marlee Tucker and Kobe Martin for statistical advice. We acknowledge the Bioanalytical Mass Spectrometry Facility within the Mark Wainwright Analytical Centre of the University of New South Wales, and particularly we thank Lewis Adler for his help with fatty acid analyses. This work has been conducted as part of Proyecto FONDECYT Postdoctorado N 3180433.

\section{Authors' contributions}

TR and AG conceived the study. AG conducted laboratory analyses where required. TR and AG wrote the paper. Both authors read and approved the final manuscript.

\section{Funding}

This research was conducted under the Australian Research Council Linkage Program LP0989933 to TR and FONDECYT Postdoctorado N 3180433 to AG.

\section{Availability of data and materials}

All data supporting the conclusions of this article are within the paper and its supporting information files.

Ethics approval and consent to participate

Samples were collected opportunistically from dead stranded animals and provided to Tracey Rogers under NSW National Parks and Wildlife Service Scientific Research Licences 10455 and SL100217.

Consent for publication

Not applicable.

\section{Competing interests}

The authors declare that they have no competing interests.

Received: 3 October 2017 Accepted: 5 July 2019

Published online: 26 July 2019

\section{References}

1. Uhen MD. Evolution of marine mammals: Back to the sea after 300 million years. Anat Rec. 2007;290(6):514-22.

2. Meiri S, Dayan T. On the validity of Bergmann's rule. J Biogeogr. 2003:30(3): 331-51.

3. Cooper CE. Biophysical properties of the pelt of a diurnal marsupial, the numbat (Myrmecobius fasciatus), and its role in thermoregulation. J Exp Biol. 2003:206(16):2771-7.

4. Irving L, Hart JS. The metabolism and insulation of seals as bare-skinned mammals in cold water. Can J Zool. 1957;35(4):497-511.

5. Castellini MA, Trumble SJ, Mau TL, Yochem PK, Stewart BS, Koski MA. Body and blubber relationships in antarctic pack ice seals: implications for blubber depth patterns. Physiol Biochem Zool. 2009:82(2):113-20.

6. Pabst DA, Rommel SA, WA ML. The functional morphology of marine mammals. In: Reynolds JE, Rommel SA, editors. Biology of marine mammals. Melbourne: Melbourne University Press; 1999. p. 15-72. 
7. Kvadsheim PH, Folkow LP, Blix AS. Thermal conductivity of minke whale blubber. J Therm Biol. 1996;21(2):123-8.

8. Elsner R. Living in water: solutions to physiological problems. In: Reynolds JE, Rommel SA, editors. Biology of Marine Mammals. Washington, D.C.: Smithsonian Institution Press; 1999. p. 73-116.

9. Budge SM, Iverson SJ, Koopman HN. Studying trophic ecology in marine ecosystems using fatty acids: a primer on analysis and interpretation. Mar Mamm Sci. 2006;22(4):759-801.

10. Miyazaki M, Ntambi JM. CHAPTER 7 - Fatty acid desaturation and chain elongation in mammals A2 - Vance, Dennis E. In: Vance JE, editor. Biochemistry of Lipids, Lipoproteins and Membranes. 5th ed. San Diego: Elsevier; 2008. p. 191-211.

11. Irving L, Schmidt-Nielsen K, Abrahamsen NS. On the melting points of animal fats in cold climates. Physiol Zool. 1957;30(2):93-105.

12. Grahl-Nielsen O, Haug T, Lindstrøm U, Nilssen KT. Fatty acids in harp seal blubber do not necessarily reflect their diet. Mar Ecol Prog Ser. 2011;426: 263-76.

13. Iverson SJ, Field C, Bowen WD, Blanchard W. Quantitative fatty acid signature analysis: a new method of estimating predator diets. Ecol Monogr. 2004;74(2):211-35.

14. Iverson SJ. Milk secretion in marine mammals in relation to foraging: can milk fatty acids predict diet? In: Boyd IL, editor. Marine mammals: advances in behavioural and population biology. Oxford: The Zoological Society of London; 1993.

15. Käkëla A, Hyvärinen $H$. Site-specific fatty acid composition in adipose tissues of several northern aquatic and terrestrial mammals. Comp Biochem Physiol A. 1996;115(4):501-14.

16. Price ER, Armstrong C, Guglielmo CG, Staples JF. Selective mobilization of saturated fatty acids in isolated adipocytes of hibernating 13-lined ground squirrels Ictidomys tridecemlineatus. Physiol Biochem Zool. 2013;86(2):205-12.

17. Harlow HJ, Varnell T. Winter changes in fatty acid composition of badger and coyote tissues. Comp Biochem Physiol B. 1980;67A:211-4.

18. Koopman HN. Phylogenetic, ecological, and ontogenetic factors influencing the biochemical structure of the blubber of odontocetes. Mar Biol. 2007; 151(1):277-91.

19. Liwanag HE, Berta A, Costa DP, Budge SM, Williams TM. Morphological and thermal properties of mammalian insulation: the evolutionary transition to blubber in pinnipeds. Biol J Linn Soc. 2012;107:774-87.

20. Hokkanen JE. Temperature regulation in marine mammals. J Theor Biol. 1990;145:465-85.

21. Guerrero Al, Negrete J, Márquez MEl, Mennucci J, Zaman K, Rogers TL. Vertical fatty acid composition in the blubber of leopard seals and the implications for dietary analysis. J Exp Mar Biol Ecol. 2016;478:54-61.

22. Guerrero Al, Rogers TL. Blubber fatty acid composition and stratification in the crabeater seal, Lobodon carcinophaga. J Exp Mar Biol Ecol. 2017;491:51-7.

23. Richardson T, Tappel AL, Gruger EH. Essential fatty acids in mitochondria. Arch Biochem Biophys. 1961;94(1):1-6.

24. West GC, Burns JJ, Modafferi M. Fatty acid composition of blubber from the four species of Bering Sea phocid seals. Can J Zool. 1979;57:189-95.

25. Garamszegi LZ, Mundry R. Multimodel-Inference in Comparative Analyses. In: Modern phylogenetic comparative methods and their application in evolutionary biology: concepts and practice. Berlin, Heidelberg: Springer; 2014. p. 305-31.

26. Burnham KP, Anderson DR. Model selection and multimodal inference: a practical information-theoretic approach. New York: Springer; 2002.

27. Martin $\mathrm{K}$, Tucker MA, Rogers TL. Does size matter? Examining the drivers of mammalian vocalizations. Evolution. 2017;71(2):249-60.

28. Laiolo P, Rolando A. The evolution of vocalisations in the genus Corvus: effects of phylogeny, morphology and habitat. Evol Ecol. 2003;17(2):111-23.

29. Freckleton RP, Harvey PH, Pagel M. Phylogenetic analysis and comparative data: a test and review of evidence. Am Nat. 2002;160(6):712-26.

30. Pagel M. The maximum likelihood approach to reconstructing ancestral character states of discrete characters on phylogenies. Syst Biol. 1999;48(3):612-22.

31. Faurby S, Svenning J-C. A species-level phylogeny of all extant and late Quaternary extinct mammals using a novel heuristic-hierarchical Bayesian approach. Mol Phylogenet Evol. 2015;84:14-26.

32. Team RC: R: A language and environment for statistical computing. Vienna: R Foundation for Statistical Computing; 2014; 2016.

33. Revell LJ. Phytools: an R package for phylogenetic comparative biology (and other things). Methods Ecol Evol. 2012;3(2):217-23.
34. Orme D: The caper package: comparative analysis of phylogenetics and evolution in R. R package version 2013, 5(2).

35. Nienaber J, Thomton J, Horning M, Polasek L, Mellish J-A. Surface temperature patterns in seals and sea lions: a validation of temporal and spatial consistency. J Therm Biol. 2010;35(8):435-40.

36. Koopman HN, Iverson SJ, Read AJ. High concentrations of isovaleric acid in the fats of odontocetes: variation and patterns of accumulation in blubber vs. stability in the melon. J Comp Physiol B. 2003;173(3):247-61.

37. Fasman GD. Handbook of biochemistry and molecular biology. Lipids, carbohydrates, steroids-3; 1975.

38. Lockyer C. Body composition of the sperm whale, Physeter catodon, with special reference to the possible functions of fat depots: marine research institute; 1991.

39. Patel S, Nelson DR, Gibbs AG. Chemical and physical analyses of wax ester properties. J Insect Sci. 2001;1(1):1-7.

40. Irving L, Peyton $\mathrm{LJ}$, Bahn $\mathrm{CH}$, Peterson RS. Regulation of temperature in Fur seals. Physiol Zool. 1962;35(4):275-84.

41. Scholander PF, Walters V, Hock R, Irving L. Body insulation of some Arctic and tropical mammals and birds. Biol Bull. 1950;99(2):225-36.

42. Henriques V , Hansen $C$. Vergleichende Untersuchungen über die chemische Zusammensetzung des thierischen Fettes1. Skandinavisches Archiv Für Physiologie. 1901;11(1):151-65.

43. Tiku P, Gracey A, Macartney A, Beynon R, Cossins A. Cold-induced expression of $\Delta 9$-desaturase in carp by transcriptional and posttranslational mechanisms. Science. 1996;271(5250):815-8.

44. Guschina IA, Harwood JL. Algal lipids and effect of the environment on their biochemistry. In: Lipids in aquatic ecosystems. New York: Springer; 2009. p. 1-24.

45. Thompson GA Jr. Lipids and membrane function in green algae. Biochim Biophys Acta. 1996;1302(1):17-45.

46. Jeffries HP. Seasonal composition of temperate plankton communities: fatty ACIDS1. Limnol Oceanogr. 1970;15(3):419-26.

47. Aguilar PS, De Mendoza D. Control of fatty acid desaturation: a mechanism conserved from bacteria to humans. Mol Microbiol. 2006;62(6):1507-14.

48. Reynolds PS. Size, shape, and surface area of beaver, Castor canadensis, a semiaquatic mammal. Can J Zool. 1993;71(5):876-82.

49. Fish FE, Smelstoys J, Baudinette RV, Reynolds PS. Fur does not fly, it floats: buoyancy of pelage in semi-aquatic mammals. Aquat Mamm. 2002;28(2): 103-12.

50. Dawson TJ, Fanning FD. Thermal and energetic problems of semiaquatic mammals: a study of the Australian water rat, including comparisons with the platypus. Physiol Zool. 1981;54(3):285-96.

51. Fish F. Influence of hydrodynamic-design and propulsive mode on mammalian swimming energetics. Aust J Zool. 1994;42(1):79-101.

52. Liwanag HE, Berta A, Costa DP, Abney M, Williams TM. Morphological and thermal properties of mammalian insulation: the evolution of fur for aquatic living. Biol J Linn Soc. 2012;106(4):926-39.

53. Bargagli R. Antarctic ecosystems: environmental contamination, climate change, and human impact, vol. 175. Berlin, Heidelberg: Springer Science \& Business Media; 2006.

54. Singleton EM, McLellan WA, Koopman HN, Pokorny A, Scharf FS, Ann Pabst D. Lipid composition and thermal properties of the blubber of Gervais' beaked whale (Mesoplodon europaeus) across ontogeny. Mar Mamm Sci. 2017:33(2):695-705.

55. Suppes G, Goff M, Lopes S. Latent heat characteristics of fatty acid derivatives pursuant phase change material applications. Chem Eng Sci. 2003;58(9):1751-63.

56. Bagge LE, Koopman HN, Rommel SA, McLellan WA, Pabst DA. Lipid class and depth-specific thermal properties in the blubber of the shortfinned pilot whale and the pygmy sperm whale. J Exp Biol. 2012; 215(24):4330-9.

57. Dunkin RC, McLellan WA, Blum JE, Pabst DA. The ontogenetic changes in the thermal properties of blubber from Atlantic bottlenose dolphin Tursiops truncatus. J Exp Biol. 2005;208(8):1469-80.

58. Dalsgaard J, St. John M, Kattner G, Müller-Navarra D, Hagen W. Fatty acid trophic markers in the pelagic marine environment. Adv Mar Biol. 2003;46: 225-340.

59. Abbott SK, Else PL, Atkins TA, Hulbert AJ. Fatty acid composition of membrane bilayers: importance of diet polyunsaturated fat balance. Biochim Biophys Acta Biomembr. 2012;1818(5):1309-17. 
60. Garland M, Sacks FM, Colditz GA, Rimm EB, Sampson LA, Willett WC, Hunter DJ. The relation between dietary intake and adipose tissue composition of selected fatty acids in US women. Am J Clin Nutr. 1998;67(1):25-30.

61. Budge SM, Cooper MH, Iverson SJ. Demonstration of the deposition and modification of dietary fatty acids in pinniped blubber using radiolabelled precursors. Physiol Biochem Zool. 2004;77(4):682-7.

62. Baylin A, Kabagambe EK, Siles X, Campos H. Adipose tissue biomarkers of fatty acid intake. Am J Clin Nutr. 2002;76(4):750-7.

\section{Publisher's Note}

Springer Nature remains neutral with regard to jurisdictional claims in published maps and institutional affiliations.

Ready to submit your research? Choose BMC and benefit from:

- fast, convenient online submission

- thorough peer review by experienced researchers in your field

- rapid publication on acceptance

- support for research data, including large and complex data types

- gold Open Access which fosters wider collaboration and increased citations

- maximum visibility for your research: over $100 \mathrm{M}$ website views per year

At $\mathrm{BMC}$, research is always in progress.

Learn more biomedcentral.com/submissions 